\title{
Compound Presentation: A Case Report of One of the Rarest Varieties- Vertex, Hand, and Feet Presentation
}

Sium AF*, Tilahun A, Mersha A and Yihun S Department of Obstetrics and Gynecology, Saint Paul's Hospital Millennium Medical College, Ethiopia

*Corresponding author: Abraham Fessehaye Sium, Saint Paul's Hospital Millennium Medical College, Department of Obstetrics and Gynecology, Addis Ababa, Ethiopia

Received: February 03, 2021; Accepted: February 25, 2021; Published: March 04, 2021

\begin{abstract}
Background: Compound presentation occurs in approximately 1/700 deliveries. Being the rarest type, there is scarce literature about the recommended management for vertex-hand-feet variety of compound presentation. We report a similar type of compound presentation.
\end{abstract}

Case Summary: A 25 years-old primigravida who claimed to be 9 months ammenorric presented with a history of pushing down pain of 12 hours duration with associated history of passage of liquor of 4 hours duration. Up on physical examination she was in active first of labor at cervical dilation of 5 centimeters and the presentation was compound- a vertex-hand-feet variety. Cesarean delivery was done after two hours of conservative management and the outcome was an alive 2300 grams male neonates with no perinatal or maternal complication.

Conclusion: In the rarest variety of compound presentation, which is a vertex, hand, and feet type, spontaneous correction is unusual if the fetus is alive and interference is usually necessary.

Keywords: Compound presentation; Vertex-hand-feet presentation; Malpresenation

\section{Background}

Compound presentation occurs in approximately $1 / 700$ deliveries. Vertex, and hand presentation is the commonest type. Being the rarest type, there is scarce literature about the recommended management for vertex-hand-feet variety of compound presentation. We report a similar type of compound presentation.

\section{Case Presentation}

A 25 years-old primigravida lady who claimed to be 9 months ammenorric presented with a history of pushing down pain of 12 hours duration and associated passage of liquor of four hours duration. She had no history of vaginal bleeding, nor headache, nor blurry of vision. Her medical, surgical, and psychosocial history was unremarkable.

Up on physical examination, her vital signs were normal and the pertinent finding was on pelvic examination. The cervix was 5 centimeters dilated, station was at minus 1 , and the presentation was compound, vertex-hand-feet type. Bedside ultrasound was done and the estimated fetal weight was 2400 grams and there was no gross fetal congenital anomaly. Two hours of conservative management was allowed with the hope to achieve spontaneous resolution of the compound presentation, but there was no progress in the cervical dilation.

With an indication of compound presentation plus arrest of cervical dilation, cesarean section was done and the outcome was alive 23000 grams male neonate with Apgar score of 7, and 8 at first and fifth minutes respectively. Intra-operatively, the diagnosis was confirmed and pelvic diameter was assessed. The obstetric conjugate was 11 centimeters. There was no difficulty encountered during extraction of the body and no perinatal complication. The patient had smooth post-operative course and her follow up visit at one week documented no abnormality with good wound healing.

\section{Discussion}

COMPOUND or complex presentation is not very rare in obstetric practice, yet it is not common enough to give an individual obstetrician considerable experience on the condition. The literature on the subject is surprisingly scarce [1]. Compound presentation is defined as presentation of a fetal extremity alongside the presenting part. It may involve one or more extremities (hand, arm and foot) with the vertex or the breech. The majority of compound presentations is represented by the fetal hand or arm presenting with the vertex [2]. Our case is one of the rarest forms of compound presentation-vertex, hand, and feet. In a case series reported in the literature, Lokenath Bhose reported 18 such cases out 91 cases of compound presentation (Table 1). As depicted in (Table 2), Goplerud and Eastman reported only 4 similar cases out of 131 cases in a similar case series, while Donald P.C and Chan reported only 3 cases out of 65 compound Table 1: Varieties of compound presentation.

\begin{tabular}{|l|c|c|}
\hline & $\begin{array}{c}\text { No. of Cases in Present } \\
\text { Series }\end{array}$ & $\begin{array}{c}\text { No. of Cases in Goplerud's } \\
\text { Series }\end{array}$ \\
\hline Vertex & $518)$ & $55(13)$ \\
Vertex and hand & $51(8)$ & $49(11)$ \\
(arm) & 3 & $4(1$ \\
Vertex hand (arm), & 3 & $2(1$ \\
and leg & $7(2)$ & $4(1)$ \\
Vertex and foot & 1 & $6(1)$ \\
Breech and hand & & 65 \\
Face and hand & 65 & \\
\hline
\end{tabular}

Austin J Obstet Gynecol - Volume 8 Issue 2 - 2021

Submit your Manuscript | www.austinpublishinggroup.com

Sium et al. () All rights are reserved
Citation: Sium AF, Tilahun A, Mersha A and Yihun S. Compound Presentation: A Case Report of One of the Rarest Varieties- Vertex, Hand, and Feet Presentation. Austin J Obstet Gynecol. 2021; 8(2): 1166. 
Table 2: Types of Compound presentation of hands and feet in present series.

\begin{tabular}{|l|c|c|c|c|}
\hline \multirow{2}{*}{\multicolumn{1}{|c|}{ Types }} & \multicolumn{3}{|c|}{ Goplerud and Estman } & \multicolumn{2}{c|}{ Present Series } \\
\cline { 2 - 5 } & No. of Cases & $\%$ & No. of Cases & $\%$ \\
\hline Hand & 55 & 90.2 & 59 & 64.8 \\
\hline Both hands & Nil & Nil & 1 & 1.1 \\
\hline Foot & 2 & 3.3 & 11 & 12.1 \\
\hline Hand and foot & 4 & 6.5 & 18 & 19.8 \\
\hline Hand and both feet & Nil & Nil & 1 & 1.1 \\
\hline Foot and both hands & Nil & Nil & 1 & 1.1 \\
\hline Associated cord prolapse & 15 & $23.07^{*}$ & 25 & 27.5 \\
\hline
\end{tabular}

Table 3: Types of compound presentation in a recent series.

\begin{tabular}{|l|c|c|}
\hline \multicolumn{1}{|c|}{ Presentation } & Breen \& Wiesmeier & Goplerud \& Eastman \\
\hline Vertex and hand & 109 & 38 \\
\hline Vertex, hand and cord & 0 & 11 \\
\hline Face and hand & 1 & 5 \\
\hline Breech and hand & 12 & 3 \\
\hline Vertex, hand and leg & 4 & 3 \\
\hline Breech, hand and cord & 0 & 1 \\
\hline Vertex and foot & 6 & 1 \\
\hline Vertex, foot and cord & 0 & 1 \\
\hline Vertex, foot, hand and cord & 0 & 1 \\
\hline Face, hand and cord & 0 & 1 \\
\hline Total & 131 & 65 \\
\hline
\end{tabular}

presentation cases (Table 3). Preterm delivery and external cephalic version are acknowledged as being among the predisposing factors, although most cases of compound presenation occur in low-risk term cephalic presenting fetuses $[2,3]$. In our case the gestational age of the pregnancy was unknown but the birth weight of the baby was 2300 grams.

The effects of a compound presentation on labour depends on the size of the fetus and the size of the maternal pelvis. This may be considered in three degrees: 1 . Where the fetus is large and the pelvis is small, a compound presentation may prevent the fetal head from entering the pelvic brim. Unless it is corrected, an obstructed labour will result. 2. Where the fetus and the pelvis are of average size, a compound presentation will cause delay in the second stage of labour. This delay is due to the prolapsed limb's interference with the normal mechanism of flexion and internal rotation of the fetal head. Correction is usually necessary. 3 . Where the fetus is small and the pelvis large, a compound presentation will have no effect on the course of labour. The fetus will be born with the hand in the prolapsed position [4]. The second effect explains our case as the baby was of average size-2300 grams and the pelvis was of average size.

The diagnosis of CP involves the palpation of a small part of the limb along with the major presenting part during vaginal examination. In early labor, the fetus may retract the extremity allowing for the spontaneous resolution of this malpresentation. On the other hand, if the extremity fails to retract spontaneously and prolapses below the fetal head, the correction of the malpresentation can be manually attempted by gently pushing the prolapsed arm upward and the head simultaneously downward by fundal pressure [5]. In our case the diagnosis was made intra-partum with one feet and one hand presenting before the vertex.

In general, the management of compound presentation consists of watchful waiting in the hope that the limb will withdraw. Interference in the form of internal version and breech extraction is often accompanied by uterine rupture and high fetal loss. However, the vertex and feet combination often poses problems. It is associated with a fetal mortality more than twice that of the vertex and hand combination. Spontaneous correction of this type of compound presentation is unusual if the fetus is alive and interference is usually necessary. Labour in such cases may become obstructed with consequent rupture of the uterus. On the rare occasion when vaginal delivery becomes possible, difficulty may arise from a nuchal hitch. This is probably due to the lower limbs taking up the space in the pelvis and impeding progress [6,7]. In our case, an attempt was made to achieve spontaneous resolution of the compound presentation and vaginal delivery by allowing two hours of conservative management.

\section{Conclusion}

In the rarest variety of compound presentation, which is a vertex, hand, and feet type, spontaneous correction of this type of compound presentation is unusual if the fetus is alive and interference is usually necessary. Hence, we recommend cesarean delivery during early labor.

\section{Declarations}

\section{Consent for publication}

A verbal informed consent was obtained from the patient for publication of this case.

\section{Availability of Supporting Data}

All supporting documents are submitted along with the case report.

\section{Authors' Contributions}

$\mathrm{AF}$ and SY contributed the introduction and case summary. AM and AT prepared the discussion and conclusion part.

\section{Funding}

This research did not receive any specific grant from funding agencies in the public, commercial, or not-for-profit sectors.

\section{Acknowledgement}

The authors would like to thank the Department of Obstetrics and Gynecology at Saint Paul's Hospital millennium Medical College, Addis Ababa, Ethiopia.

\section{References}

1. Compound Presentation a Review of 91 Cases by Lokenath Bhose MB. Lecturer Chittaranjan Sevasadan College of Obstetrics, Gynaecology and Child Health, Calcutta, India). 1961; 68: 307-314.

2. Cruikshank DP, White CA. Obstetric malpresentations: twenty years' experience. Am J Obstet Gynecol. 1973; 116: 1097-1104.

3. A Study of 65 Cases of Comipound Presentation by Donald PC. Chan MB. Lecturer in Obstetrics and Gynaecology, Honig Konzg University). 
4. Compound Presentation W. LG. Quinlivan, MB. Woodstock, Ont.

5. Labor and delivery. Editors. In: Cunningham FG, Hauth JC, Leveno KJ, et al. Williams Obstetrics (22 ${ }^{\text {nd }}$ edition). 414 New York: McGraw-Hill. 2005.

6. Ang LT. Compound Presentation Following External Version. 1978; 18: 213214.
7. James LB, Edward W. Compound Presentation: A Survey of 131 Patients, Obstetrics \& Gynecology. 1968; 32: 419-422. 